\title{
A COMPARATIVE STUDY TO EVALUATE THE EFFECT OF PUERARIN VERSUS SIMVASTATIN AS OSTEOCONDUCTIVE MATERIAL FOR MAXILLARY SINUS AUGMENTATION: A PROSPECTIVE RANDOMIZED CONTROL CLINICAL TRIAL
}

\author{
Ayman Gouda*, Ghada Abdel Monim* and Mohammed Khashaba**
}

\begin{abstract}
Dental implant is an effective treatment method for oral rehabilitation. Still, it has to be modified because of unfavorable environments such as excessive alveolar bone loss and sinus pneumatization. Maxillary sinus grafting is a standard procedure used to correct such unfavorable conditions in the posterior maxilla.
\end{abstract}

Purpose: to assess and compare changes in height and percentage of Puerarin versus simvastatin as osteoconductive materials following sinus augmentation.

Basic procedures: twenty patients with edentulous posterior maxilla were selected and equally grouped into 2 groups. Both groups underwent antral augmentation using either Puerarin on Fisiograft sponge carrier graft (group A) or combination of simvastatin and $\beta$-TCP (group B). The amount and percentage of bone graft were evaluated radiographically. Assessment occurred at period intervals 1-week and 6-month postoperatively. Data were presented as mean and standard deviation (SD) values. For non-parametric data, Mann-Whitney U test was used to compare between the two groups. Qualitative data were presented as frequencies and percentages. Fisher's Exact test was used for comparisons between the groups. The significance level was set at $\mathrm{P} \leq 0.05$. Main finding: there was decrease in the amount and percentage of bone graft height by $2.5 \mathrm{~mm}$, $19.7 \%$ (for Group A) and $3.2 \mathrm{~mm}, 22.4 \%$ (for Group B) at the end of the 6 months period without significant difference in both group $(\mathrm{P}$-value $=0.054$, Effect size $=0.919)$ and $(\mathrm{P}$-value $=0.151$, Effect size $=0.678)$, respectively.

Conclusion: Puerarin and Simvastatin are clinically beneficial and safe bone grafting materials in cases of antral augmentation.

KEY WORDS: Sinus floor augmentation, grafting material, bone regeneration, Simvastin, Puerarin, dental implant

\footnotetext{
* Lecturer of Oral and Maxillofacial Surgery, Faculty of Dentistry, Cairo University

** Assistant Professor of Oral and Maxillofacial Surgery, Faculty of Dentistry, Cairo University
} 


\section{INTRODUCTION}

Following tooth extraction and pneumatization of the maxillary sinus, alveolar bone resorption particularly in the posterior maxilla makes implant placement more difficult by sacrificing the quantity and consistency of the bone required to ensure the stability of dental implants. Several procedures have been suggested to overcome these issues, including the use of short implants and vertical augmentation with elevation of the sinus floor. ${ }^{[1]}$ The treatment of choice for the most appropriate surgical intervention for rehabilitation of posterior maxillary ridge with implants is influenced by the vertical height of the residual alveolar bone, the amount of lifting required, local intra-sinus anatomy and the number of teeth to be replaced, in addition to the surgeon's preference. ${ }^{[2]}$

The use of short implants is one of the minimally invasive treatment options for the rehabilitation of edentulous posterior maxilla in order to overcome the issue of insufficient bone quantity, with the key benefits of preventing entrance into the sinus cavity, reducing the costs and the operating time. Patients with severe parafunctional habits and poor bone density with inadequate bone height can constitute an exception. A variety of surgical techniques for sinus lifting have been used either by transalveolar sinus floor elevation or through a lateral window technique with or without bone grafting augmentation material. These techniques considered a reliable procedures especially in cases of sever resorption ridge height as they provides a vertical dimension by increasing the volume of new bone and enhancing the dimension of the residual alveolar ridge before implant placement allowing high survival rate implant in the posterior maxilla ${ }^{[3-5]}$

Lateral window Sinus lifting technique has been recognized as one of successful technique for restoring the posterior maxillary area with severely resorbed ridge, resulting in a high survival rate of implants. The most common drawback of this technique is intraoperative sinus membrane perforation which has been established as a significant risk factor leading to postoperative infection and graft failure. ${ }^{[2,6-9]}$

Some scholars have suggested modifying the lateral window operation procedure in order to reduce the incidence of membrane perforation and increase the height of the membrane by means of hydraulic pressure techniques, crest-free drills and the use of piezoelectric equipment to cut the bony window with great simplicity and precision while maintaining the integrity of the membrane. ${ }^{[10-13]}$

Maxillary sinus floor augmentation with different types of grafting materials including autograft, allograft, xenograft, alloplastic materials and growth factors after sinus membrane elevation has been used. It was considered to be one of the surgical procedures for enhancing vertical alveolar bone height, particularly in the case of atrophied posterior maxilla prior to or in conjunction with implant placement, with highly predictable and successful outcomes. ${ }^{[13-16]}$

As the grafting material should be osteogenic, osteoinductive, osteoconductive, biocompatible and volumetrically stable to provide us with the optimal outcome so, selecting the ideal grafting material for the sinus augmentation is a controversial subject. Although autogenous bone is considered the gold standard of all graft materials because of its high osteogenic potential, it has several drawbacks. Such as limited amounts of available bone for grafting procedures, donor-site morbidity and the expected biologic behavior (neovascularization and resorption) its rapid resorption in both animal and human maxillary sinus graft studies. ${ }^{[17,18]}$ Taking in consideration these disadvantages, various allografts, xenografts and alloplastic materials are used to substitute autogenous bone

While using the different biomaterials, it is advisable to know their resorption profiles, and this profile should closely match the bone formation rate at the regeneration or implant sites. The resorption time and ultimate replacement of these graft materials with newly formed bone are not fully understood. ${ }^{[19,20]}$ 
Simvastatin is derived synthetically from fermentation product of Aspergillus terreus. It is a lipid-lowering agent that used orally to treat hypercholesterolemia and hyperlipidemia it has several effects including prevention of bone resorption and anabolic effects on bone. They also have anti-inflammatory effects they promote osteoblastic differentiation through increased expression of vascular endothelial growth factor (VEGF) in osteoblasts. ${ }^{[21]}$ Simvastatin also inhibits osteoclastic differentiation induced by receptor activator of nuclear factor Kappa-beta ligand (RANKL). Several studies on rats and dogs showed promising results regarding use of simvastatin as a factor inducing new bone formation in regenerative processes. These studies showed promising results for use of simvastatin for bone formation. ${ }^{[22-26]}$

Puerarin is the major bioactive ingredient derived from the root of the Puerarin lobata (Willd.) Ohwi, widely known as Gegen (Chinese name) in traditional Chinese medicine ${ }^{[27]}$ For the past several decades, Puerarin has been used as one of three major isoflavonoid compounds, that considered the earliest and most important crude herbs utilized in Chinese medicine for various medicinal purposes as treat fever, diarrhea, emesis, cardiac dysfunctions, liver injury, weight loss, and toxicosis due to its abilities to inhibit calcium influx, improve microcirculation, reduce insulin resistance, scavenge oxygen free radicals, counteract cell death, inhibit alcohol intake, and so on. ${ }^{[28-30]}$ In recent years researchers have paid more attention to Puerarin because of its possible role in the prevention of osteoporosis. The findings indicate Puerarin may have the potential to promote bone formation. ${ }^{[31-33]}$

Since Maxillary sinus elevation and augmentation provides a predicted outcome of the regenerative loss of osseous structure in the posterior maxilla, which offers many advantages for patients with long-term performance at implant sites ${ }^{[1,5,7,13]}$, and due to limited numbers of human studies on effects of Puerarin and simvastatin administration as an osteoinductive material for regenerative processes. So, our current study designed to assess and compare the height and percentage changes of Puerarin versus Simvastin when combined with beta tricalcium phosphate ( $\beta$-TCP) as osteoconductive materials following maxillary sinus augmentation with delayed implant placement.

\section{PATIENTS AND METHODS}

A randomized control trial conducted on twenty patients with edentulous posterior maxilla. The patient divided randomly into two groups. Both groups underwent maxillary sinus lifting procedure and augmentation using either Puerarin ${ }^{1}$ on Fisiograft $^{2}$ sponge carrier graft (group A) or combination of simvastatin $^{3}$ and $\boldsymbol{\beta}$-TCP ${ }^{4}$ (group B). The study was a double blind one (participants and outcome assessors were blinded throughout the study).

All patients were selected according to the following criteria:

- The selected patients had edentulous posterior maxilla with insufficient bone height (available bone $\leq 5 \mathrm{~mm}$ ) from the edentulous crest to the maxillary sinus floor for implant placement indicating the need for maxillary sinus floor augmentation before implantation.

- The patients were apparently free from any sinus and/or systemic disease that may jeopardize normal healing of bone, and adversely affect predictable outcome.

Clinical examination was conducted to demonstrate that all patients fulfilled the selected criteria. Cone beam computer tomography (CBCT) ${ }^{5}$ was performed Pre-operatively for all selected patients in order to evaluate and measure the amount of the residual bone height available in the maxillary

1. Puerarin- Daidzein-8-C-glucoside, Gegensu Zhusheye, 2mL:100mg, Shandong Fangming Pharmaceutical Group

2. Fisiograft spugna- Via Cimarosa, 85 - 40033 Casalecchio di Reno (Bologna)- Italy

3. Simvastatin - Supplied by Molekula Limited. Brickfields Business Park. Gillingham, Dorset - United Kingdom

4. Bioresorb classic - Herrlichkeit 4.28199 Bermen - Germany.

5. Scanora3D, Soredex- Nahkelantie 160, P.O. Box 148, Tuusula-Finland, 15 mA, 85 KV. 
posterior edentulous area from the crest of the ridge to the floor of the sinus. Fabrication of a study model and construction of radiographic stent for every selected patient in both groups was performed. The radiographic stent was then used as a surgical stent during implant placement in the second stage surgery.

\section{First stage surgery:}

Puerarin/Fisiograft carrier preparation: (For group A)

- It consisted of two components: Puerarin and which provided the matrix for delivery of Puerarin. Three dry sponges $1.2 \mathrm{~cm} \times 0.5 \mathrm{~cm}$ $\mathrm{x} 1.0 \mathrm{~cm}$ Fisiograft sponges were injected with $4 \mathrm{ml}$ of Puerarin solution using sterile syringe (50mg/mL concentration). (fig 1 )

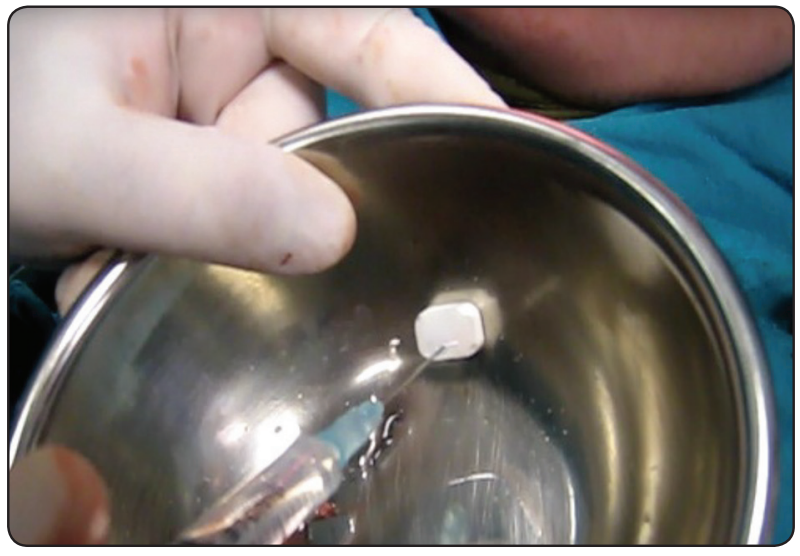

Fig. (1) Showing the injection of Puerarin solution into Fisiograft sponge.

\section{A) B.TCP- Simvastatin complex Preparation: (For group B)}

- Simvastatin powder was dissolved in $97 \%$ ethanol.

- Then a dropper was used to apply the solution to the $\beta$-TCP particles so that each gram of $\beta$-TCP contained $7.21 \mathrm{mg}$ of Simvastatin.
- After this, sufficient time was given to allow a complete evaporation of ethanol.

- The entire procedure was performed under a laminar flow hood in order to ensure complete sterile conditions.

\section{Open sinus lifting procedure (for both groups)}

All the surgical procedures were performed under local anesthesia ${ }^{1}$ using maxillary nerve block with buccal and palatal infiltration. Then the maxillary sinus floor elevation using the lateral window technique was performed. Access to the lateral wall of the sinus was achieved via a mucosal crestal incision with an anterior releasing incision and a full thickness flap elevation. A bone window was outlined using piezoelectric device that was operated at a frequency of 28 to $36 \mathrm{kHz}$ with tip amplitude that was modulated, producing micro-vibrations .Complete osteotomy along the perimeter of the osseous window until the Schneiderian membrane. The Schneiderian membrane was carefully elevated till the desired height.

\section{- Grafting of the maxillary sinus.}

- For group A, 200mg of Puerarin on resorbable Fisiograft were compacted and packed against inferior walls and to the sides of the antral until the new available volume created was filled. (Fig 2)

- For group B, Simvastatin with $\beta$-TCP was used to fill all of the new available volume after being hydrated with saline. (Fig 3)

Resorbable collagen membrane ${ }^{2}$ was used to cover the osteotomy window. Finally, the flap was returned into position and sutured using 3/0 black silk suture.

Postoperative care: All the patients were recalled a week after surgery for suture removal.

1. UbistesinTM forte, 3M ESPE, Espe Platz, Seefeld - Germany

2. Biocollagen, Bioteck, Torquato Taramelli, 23, 20025, Legnano MI - Italy. 


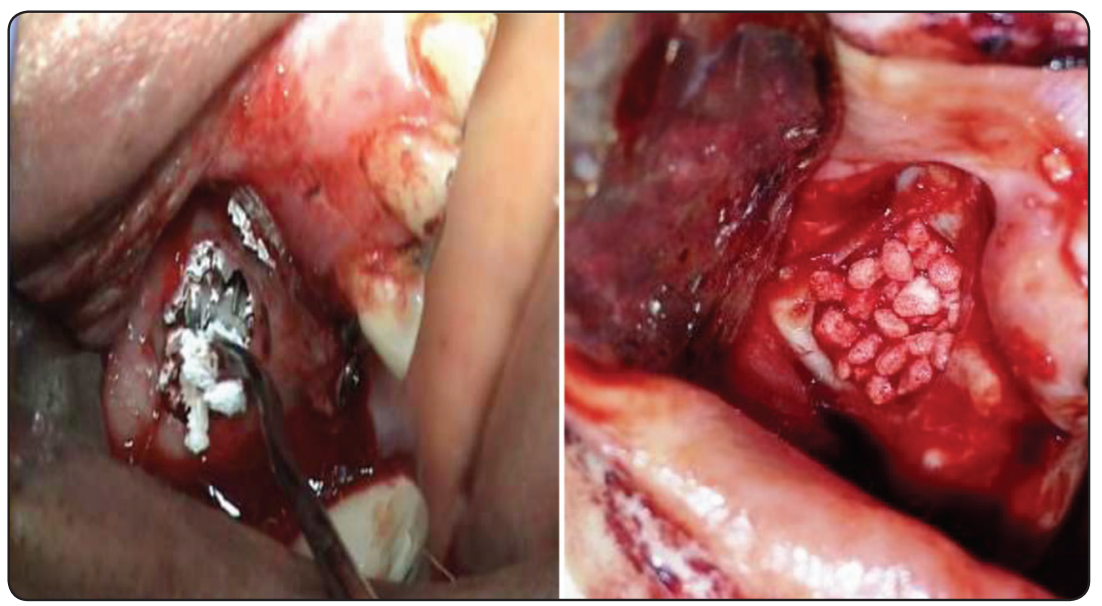

Fig. (2\&3) Showing grafting procedure of the sinus using Puerarin on resorbable Fisiograft for group A (left photo) and Simvastatin with $\beta$-TCP for group B (right photo)

Wound was thoroughly examined for any sign of inflammation or infection. Postoperative instructions and medication including Augmentin $\mathbf{1 g}^{\mathbf{1}}$ (one tablet every $12 \mathrm{~h}$ for one week), Ultrafen $\mathbf{6 0 0 \mathbf { m g } ^ { 2 }}$ (one tablet every $12 \mathrm{~h}$ for one week) and Afrin nasal spray $^{3}$ (2-3 sprays every $12 \mathrm{~h}$ for one week) were prescribed for the patients. All Patients were examined clinically on a weekly basis for the first month, then at 2,6 months postoperatively.

\section{Post-operative radiographic evaluation:}

Postoperative CBCT radiographs were taken for every patient 1 week and 6 months postoperatively at first stage surgery to assess the bone graft and prior to the second stage surgery. The radiographs were made with the same machine and same exposure parameters. Image reconstruction was performed using special software \{Ondemand3D software (cybermed Inc -Korea)\}. Radiographic evaluation was focused on the change in bone quantity and its percentage for each group. Sinus floor were traced and the measures were recorded in 1 week and 6 months postoperatively. All measures were performed at the highest point of new sinus floor using the software with a millimeter scale. (Fig 4,5)

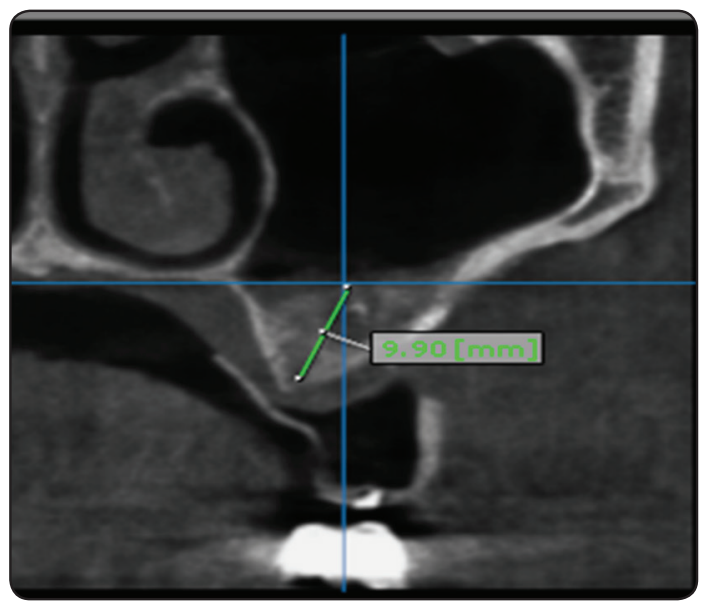

Fig. (4) Showing the linear measurement for bone height (group A) 6 months postoperative using the OnDemand 3D software

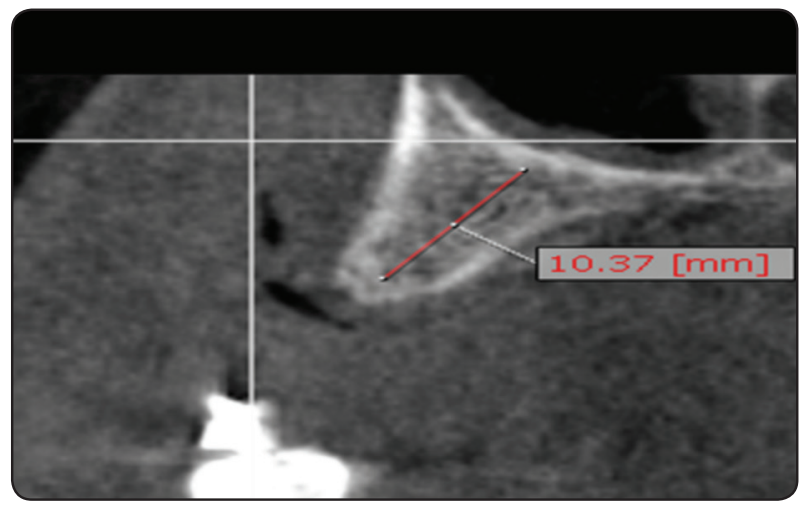

Fig. (5) Showing the linear measurement for bone height (group B) 6 months postoperative using the OnDemand 3D software.

1. Each tablet contains $875 \mathrm{mg}$ amoxicillin and $125 \mathrm{mg}$ Clavulanic acid by Glaxosmithkline, Fifth district - New Cairo, Cairo - Egypt.

2. Each tablet contains $600 \mathrm{mg}$ Ibuprofen by Glaxosmithkline - Fifth district - New Cairo, Cairo - Egypt.

3. Oxymetazoline $\mathrm{HCl}$ ) $0.05 \%$ Nasal Spray $20 \mathrm{ml}$ by Medical Union Pharmaceuticals - Egypt. 10. 


\section{Second stage surgery:}

Second stage surgery was performed 6-months for implant placement after sinus lift procedure. Under local analgesia a crestal incision was performed and a full-thickness mucoperiosteal flap was reflected the implant ${ }^{1}$ was screwed using ratchet wrench till intra-osseous portion of implant was completely inserted in the bone. The cover screw was screwed into the fixture. Finally, the flap was returned into position and sutured using 3/0 vicryl suture.

\section{Ancillary and post-trial care}

After the Osseo-integration of the implants, the abutments were attached and prosthetic replacement of the teeth was performed.

\section{Statistical Analysis}

Numerical data were explored for normality by checking the distribution of data and using tests of normality (Kolmogorov-Smirnov and ShapiroWilk tests). Age and bone height measurements data showed normal (parametric) distribution while changes and percentage changes in bone height showed non-normal (non-parametric) distribution. Data were presented as mean and standard deviation (SD) values. For parametric data, Student's t-test was used to compare between mean ages values in the two groups. Repeated measures ANOVA test was used to compare between the two groups as well as to study the changes by time within each group. Bonferroni's post-hoc test was used for pairwise comparisons when ANOVA test is significant. For non-parametric data, Mann-Whitney U test was used to compare between the two groups. Qualitative data were presented as frequencies and percentages. Fisher's exact test was used for comparisons between the groups. The significance level was set at $\mathrm{P} \leq 0.05$. Statistical analysis was performed with IBM SPSS ${ }^{2}$ Statistics for Windows, Version 23.0. Armonk, NY: IBM Corp.

\section{RESULTS}

Twenty patients were included in this study, ten patients in each group. In Group $\mathbf{A}$ the average range of age was 46.9 while in Group B was 42.2 with No statistically significant difference between mean age values and gender distributions in the two groups. (Table 1)

Clinical results showed that all cases proceeded uneventful with the complete healing of the surgical site and resolution of all expected postoperative inflammation.

TABLE (1) Mean, standard deviation (SD), frequencies (n), percentages and results of Student's t-test and Fisher's Exact tests for comparisons of demographic data in the two groups

\begin{tabular}{cccc}
\hline & $\begin{array}{c}\text { Puerarin/ } \\
\text { Fisiograft } \\
(\mathrm{n}=10)\end{array}$ & $\begin{array}{c}\beta \text {-TCP with } \\
\text { Simvastatin } \\
(\mathrm{n}=10)\end{array}$ & $P$-value \\
\hline $\begin{array}{c}\text { Age (Years) } \\
\text { Mean (SD) }\end{array}$ & $46.9(7.5)$ & $42.2(6.4)$ & 0.149 \\
\hline $\begin{array}{c}\text { Gender [n (\%)] } \\
\text { Male }\end{array}$ & $6(60)$ & $5(50)$ & 1.000 \\
Female & $4(40)$ & $5(50)$ & \\
\hline
\end{tabular}

*: Significant at $P \leq 0.05$

\section{Radiographic results:}

\section{Bone height measurement $(\mathrm{mm})$ results:}

Pre-operatively; there was no statistically significant difference between mean basal bone height measurements in the two groups $(P$-value $=$ 0.114 , Effect size $=0.133$ ).

As regards graft height immediately postoperative as well as after 6 months; there was no statistically significant difference between the two

1. IBS implant, Innobiosurg co., Ltd, 518 Yongsan-dong (Daedeok Techno Vally) Korea

2. IBMVR SPSS StatisticsVR version 20 for windows: VR IBM Corporation, NY, USA. VR SPSS, Inc., an IBM Company. 
groups $(P$-value $=0.056$, Effect size $=0.208)$ and $(P$-value $=0.104$, Effect size $=0.14)$, respectively.

As regards the changes by time, there was a statistically significant decrease in graft height after 6 months in both groups $(P$-value $<0.001$, Effect size $=0.874)$ and $(P$-value $<0.001$, Effect size $=$ 0.924), respectively. (Table 2) (Fig 6)

\section{Amount and percentage of decrease in graft height results:}

There was no statistically significant difference between mean amount and percentage of decrease in graft height in the two groups $(P$-value $=0.054$, Effect size $=0.919)$ and $(P$-value $=0.151$, Effect size $=0.678)$, respectively. $($ Table 3$)($ Fig 7,8$)$

TABLE (2) Descriptive statistics and results of repeated measures ANOVA test for comparison between bone and graft height measurements $(\mathrm{mm})$ in the two groups and the changes by time within each group

\begin{tabular}{|c|c|c|c|c|c|c|}
\hline \multirow[t]{2}{*}{ Time } & \multicolumn{2}{|c|}{$\begin{array}{l}\text { Puerarin/ Fisiograft } \\
\qquad(\mathrm{n}=10)\end{array}$} & \multicolumn{2}{|c|}{$\begin{array}{l}\beta \text {-TCP with } \\
\text { Simvastatin } \\
\quad(n=10)\end{array}$} & \multirow[t]{2}{*}{$P$-value } & \multirow{2}{*}{$\begin{array}{c}\text { Effect size } \\
\text { (Partial Eta Squared) }\end{array}$} \\
\hline & Mean & SD & Mean & $\mathrm{SD}$ & & \\
\hline Pre-operative (Basal bone) & 4.47 & 0.44 & 3.98 & 0.83 & 0.114 & 0.133 \\
\hline Graft height (Immediate post-operative) & 12.17 & 1.6 & 14.16 & 2.04 & 0.056 & 0.208 \\
\hline Graft height 6 months & 9.69 & 1.74 & 10.96 & 1.56 & 0.104 & 0.14 \\
\hline$P$-value (Changes by time in graft height) & \multicolumn{2}{|c|}{$<0.001 *$} & \multicolumn{2}{|c|}{$<0.001 *$} & & \\
\hline Effect size (Partial Eta Squared) & \multicolumn{2}{|c|}{0.874} & \multicolumn{2}{|c|}{0.924} & & \\
\hline
\end{tabular}

\section{*: Significant at $P \leq 0.05$}

TABLE (3) Descriptive statistics and results of Mann-Whitney U test for comparison between amount and percentage of changes in graft height measurements $(\mathrm{mm})$ after 6 months in the two groups

\begin{tabular}{|c|c|c|c|c|c|c|}
\hline \multirow{2}{*}{$\begin{array}{l}\text { Change in graft height } \\
\text { after } 6 \mathrm{~m}\end{array}$} & \multicolumn{2}{|c|}{$\begin{array}{l}\text { Puerarin/ Fisiograft } \\
\qquad(\mathrm{n}=10)\end{array}$} & \multicolumn{2}{|c|}{$\begin{array}{l}\beta \text {-TCP with Simvastatin } \\
\qquad(\mathrm{n}=10)\end{array}$} & \multirow[t]{2}{*}{$P$-value } & \multirow[t]{2}{*}{ Effect size (d) } \\
\hline & Mean (SD) & Median (Range) & Mean (SD) & Median (Range) & & \\
\hline Amount of change (mm) & $-2.5(2)$ & $-1.9(-7.6--0.6)$ & $-3.2(1)$ & $-2.9(-4.6--2)$ & 0.054 & 0.919 \\
\hline Percentage of change $(\%)$ & $-19.7(12.9)$ & $-16.8(-52.1--0.4)$ & $-22.4(5.5)$ & $-22.3(-30.2--16.5)$ & 0.151 & 0.678 \\
\hline
\end{tabular}

*: Significant at $P \leq 0.05$ 


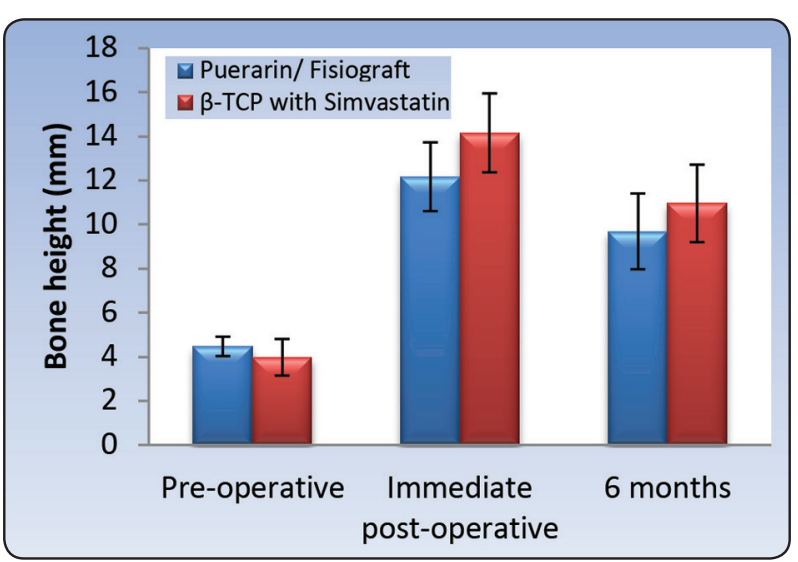

Fig. (6) Bar chart representing mean and standard deviation values for bone height measurements in the two groups

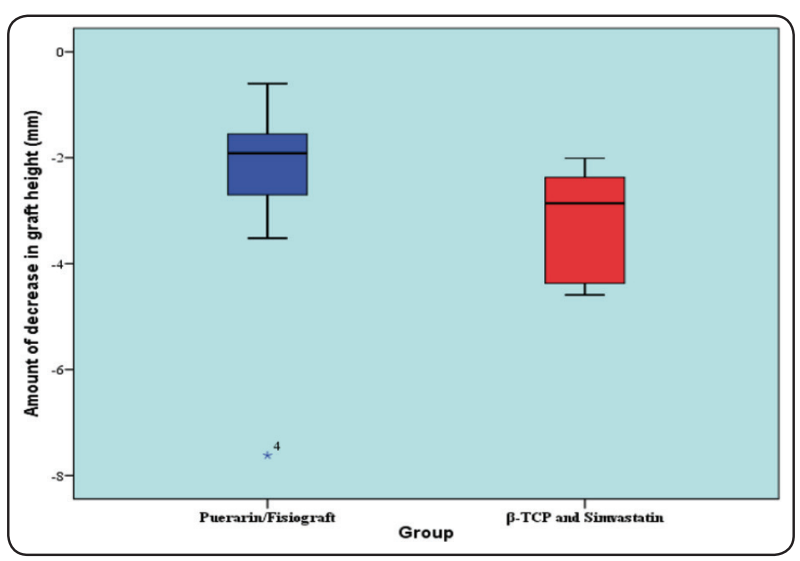

Fig. (7) Box plot representing median and range values for amount of decrease in graft height measurements in the two groups (Star represents outlier)

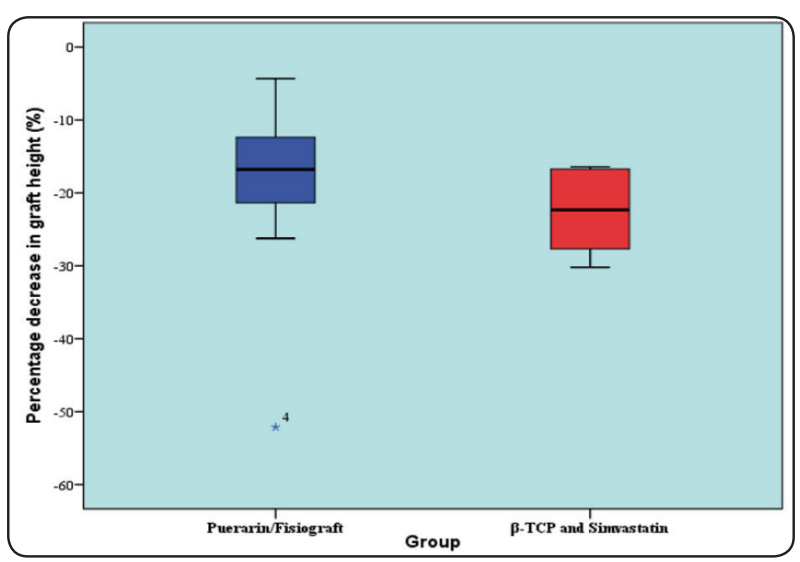

Fig. (8) Box plot representing median and range values for percentage decrease in graft height in the two groups (Star represents outlier)

\section{DISCUSSION}

Rehabilitation of posterior maxillary region in conjunction with dental implant is usually one of the most challenging and technically sensitive surgical procedures due to maxillary sinuses pneumatization, post-extraction bone resorption, and unfavorable quality of alveolar bone. Therefore, Maxillary sinus elevation and augmentation with different materials consider one of potential solutions for regenerating lost osseous structure in the posterior maxilla and offers the patient many advantages for long-term success at implant sites. ${ }^{[34-37]}$ Since the number of human studies on the effects of administration of simvastatin and Puerarin as osteoinductive material for regenerative processes is limited. So, our research was therefore planned to test and compare the effects of Puerarin /Fisiograft versus Simvastin combined with beta-tricalcium phosphate $(\beta-\mathrm{TCP})$ as osteoconductive content on bone formation during maxillary sinus augmentation for implant placement.

Elevation of the sinus floor has different treatment options in the literatures. ${ }^{[3-5]}$ in the present study Strict and meticulous procedure was performed during sinus elevation augmentation surgery. We utilized the lateral window technique in agreement with previous studies ${ }^{[6,38,39]}$ Which considered by using lateral window technique sufficient amount of the graft material will be allowed to be introduced into the sinus, direct access to the sinus floor will be provided, and the alveolar ridge will preserves. Also piezoelectric device was used, none of the cases showed membrane perforation or signs of infection of the area of surgery or a stitch abscess. This was in in accordance with Jordi et al ${ }^{[40]}$ and Toscano et al ${ }^{[41]}$, who considered the osteotomy with piezoelectric device is simpler, safer and an effective means that promote making a smaller bone window without causing injury to the soft tissue and minimizing the potential risk for intraoperative complications during lateral window approach compared to using conventional rotary instruments. 
Since the introduction of dental implants, bone grafting has become an important procedure required specially for the treatment of patients with limited bone availability. In our study sinus lifting with graft material was performed primarily then implant placement was performed 6 months later as $\leq 5 \mathrm{~mm}$ of bone between the crest of the ridge and the floor of the maxillary sinus occurred which can't give primary stability to the implant. This is in agreement with the studies of Mish et al ${ }^{[42]}$ and Raghoebar et al ${ }^{[43]}$ who determined the available alveolar bone height for implant placement as $5 \mathrm{~mm}$ at least in the superior inferior direction, to allow the shoulder of the implants to be placed within it and be supported by the remaining alveolar bone, thus immediate stability of the implants and bone grafts were achieved. This was further emphasized by $\boldsymbol{B a b b u s h}^{[44]}$ who determined a minimum of 6 $\mathrm{mm}$ remaining between the crest of the residual alveolar ridge and the floor of the sinus for grafting with simultaneously implants placement to obtain primary stabilization of the implants.

Bone regeneration includes three essential components: firstly, signaling molecule; secondly, scaffold that acts as osteoconductive surface to support osteoblastic bone formation; and thirdly, cells responsible for bone formation. The "in situ tissue regeneration approach" involves inducing new tissue formation by specific scaffolds with external stimuli that are used to stimulate body's own cells and promote local tissue repair. ${ }^{[5]}$ the bone substitute necessary for each bone regeneration procedure must therefore be selected based on the characteristics of individual, and the surgical procedure itself. Factors such as the host residual bone's osteogenic capacity, patient systemic health, and morphology of the defect can delimit the optimal bone replacement for each case. ${ }^{[46,47]}$

As Puerarin is one of the major phytoestrogens isolated from the root of a wild leguminous creeper, Puerarin lobata (Kudzu, Willd.) ${ }^{[27]}$ Our present study was designed to use Puerarin/Fisiograft as graft material to augment the maxillary sinus (for Group A) in accordance to those previous studies ${ }^{[31-33]}$ which suggests that Puerarin could have the ability to facilitate bone formation. Zhang et al ${ }^{[48]}$, Wong et $\boldsymbol{a l}^{[49]}$ and Wang et $\boldsymbol{a l}^{[50]}$ found that Puerarin acts as an osteoblasts growth stimulator promoting the osteoblast bone formation both in vitro and in vivo. In addition, Urasopon et al ${ }^{[51]}$ found that it could also prevent bone loss in castrated male rats. Yang et $\boldsymbol{a l}^{\left[{ }^{[52]}\right.}$ indicate Puerarin-loaded titanium surfaces promote accelerated osteogenic differentiation of preosteoblasts, which has the potential to improve the nature of osseointegration.

Simvastatin derived synthetically from a fermentation product of Aspergillus terreus was used (for Group B) in agreement with previous studies ${ }^{[21-25]}$ that suggested the beneficial effects of simvastatin on bone formation. The direct effect of statins on bone was discovered for the first time by Mundy et $\boldsymbol{a l}^{[53]}$ in 1999. Their study, along with others, suggests that statins administered either locally or systemically, act as potent stimulators of bone formation and regeneration. Simvastatin was used with $\beta$-TCP in this study in accordance with Rojbani et al ${ }^{[54]}$ who found that simvastatin favorably modifies the material character by stimulating bone formation and concluded that combining a bone substitute that has osteoconductive properties as $\alpha$-TCP, $\beta$-TCP and HA with simvastatin stimulates bone regeneration, affects degradability of $\alpha$-TCP and $\beta$-TCP and enhances bone formation in calvarial defects of rats. Also Gouda et al ${ }^{[55]}$ found that amount of newly formed bone was higher in the simvastatin group combined with $\beta$-TCP when compared to the $\beta$-TCP alone and concluded that Simvastatin is safe to be used in sinus lift in human with promising osteoinductive capacity.

As the present study was aimed to evaluate the bone height by using CBCT scans at the site of either augmented maxillary sinus with Puerarin/ Fisiograft (group A) or Simvastatin combined with $\beta$-TCP (group B) up to a period of six months, 
CBCT results showed that time played an important role in the healing procedure of the bone. At immediate postoperative radiograph, we found a significant increase in the bone height immediately after grafting due to increase in the radiopacity of the graft than normal bone in both groups. This was followed by a decrease in the bone height between the immediate postoperative and the 6-months follow up without statistically significant difference between the two groups. These findings is in accordance with Hatano et al. ${ }^{[56]}$ and $X \boldsymbol{u}$ et $\boldsymbol{a l}^{[57]}$ who found that resorption of the graft material and repneumatization of the maxillary sinus which may be caused by positive intra sinus air pressure might have a role in the activation of the osteoclasts that cause absorption and marked decrease in the bone height that has occurred after 6 months follow up. Also Wang et al.$^{[50]}$ concluded that the resorption of implanted grafts in the elevated sinus is a common phenomenon, which may occur even in autologous bone. The exact mechanism is unclear, but it may be associated with air pressure in the sinus. But these findings were in consistent with the results of Panagiotou et al. ${ }^{\left[{ }^{[8]}\right.}$ who reported no difference between the alveolar bone height results obtained immediately and 6 months after augmentation. This may be justified by the application of different bone graft materials.

Regarding to the change in the amount and percent of graft height, our result revealed that decrease in the amount and percentage of bone graft height by $2.5 \mathrm{~mm}, 19.7 \%$ (for Group A) and 3.2 $\mathrm{mm}, 22.4 \%$ (for Group B) at the end of the 6 months period without significant difference in both group $(P$-value $=0.054$, Effect size $=0.919)$ and $(P$-value $=0.151$, Effect size $=0.678)$, respectively. This may attributed to usage dose of the graft material used in this study. As in group A a dose of 200mg Puerarin was used as $4 \mathrm{~mL}(50 \mathrm{mg} / \mathrm{mL})$. This was according to manufacturer recommendation as the minimal safe dose for systemic circulation. The normal safe dose for systemic circulation is $200-400 \mathrm{mg}$ daily, while in group B the dose of Simvastatin (each gram of $\beta$-TCP contained $7.21 \mathrm{mg}$ of Simvastatin) was used based on studies performed by and Rojabani et al ${ }^{[54]}$ and Nyan et al ${ }^{[59]}$ in which they used $0.1 \mathrm{mg}$ Simvastatin per $14 \mathrm{mg}$ either $\alpha$ and /or $\beta$-TCP. Other studies, Allon et al ${ }^{[60]}$ Chauhan et al. ${ }^{\left[{ }^{[1]}\right]}$ that used higher dose of Simvastatin $(0.5 \mathrm{mg})$ with other scaffolds (bioglass and collagen graft) reported positive result with significant increase in bone formation, yet this dose/scaffold combination was selected as it is the lowest dose that was reported in the literature to induce bone formation since it was the first time in the lecturer to use Simvastatin in human sinus and its effect on the sinus lining is still unknown.

Although large variety of grafting materials have been tested for maxillary sinus floor augmentation in both clinical and experimental studies ${ }^{[13-19]}$, but our research was the first that compare Puerarin versus Simvastatin as a grafting material for maxillary sinus floor augmentation. So, we cannot compare our finding with other studies. Our findings suggested that Puerarin and Simvastatin is clinically beneficial and safe alternatives bone grafting materials in cases of maxillary sinus augmentation. Further clinical studies are warranted to assess the histological and radiological outcomes of Puerarin and simvastatin, determine the optimal therapeutic doses or delivery forms for sinus augmentation and the effectiveness for humans for bone regeneration.

\section{REFERENCES}

1. Khehra A, Levin L. Maxillary sinus augmentation procedures: a narrative clinical review. Quintessence Int. 2020; 51:578-584.

2. Lozada JL, Goodacre C, Al-Ardah AJ, Garbacea A. Lateral and crestal bone planing antrostomy: a simplified surgical procedure to reduce the incidence of membrane perforation during maxillary sinus augmentation procedures. J Prosthet Dent. 2011; 105:147-53.

3. Nedir R, Nurdin N, Abi Najm S, El Hage M, Bischof M. Short implants placed with or without grafting into atrophic sinuses: the 5-year results of a prospective randomized controlled study. Clin Oral Implants Res. 2017; 28: 877-886. 
4. Bechara S, Kubilius R, Veronesi G, et al. Short (6-mm) dental implants versus sinus floor elevation and placement of longer (10-mm) dental implants: a randomized controlled trial with a 3-year follow-up. Clin Oral Implants Res. 2017; 28:1097-1107.

5. Starch-Jensen T, Jensen JD. Maxillary Sinus Floor Augmentation: a Review of Selected Treatment Modalities. J Oral Maxillofac Res. 2017;8 (3):e3. Published 2017 Sep 30.

6. Kao SY, Lui MT, Cheng DH, Chen TW. Lateral trap-door window approach with maxillary sinus membrane lifting for dental implant placement in atrophied edentulous alveolar ridge. J Chin Med Assoc. 2015; 78:85-88.

7. Al-Dajani M. Recent trends in sinus lift surgery and their clinical implications. Clin Implant Dent Relat Res. 2016; 18:204-12.

8. Testori T, Yu SH, Tavelli L, Wang HL. Perforation Risk Assessment in Maxillary Sinus Augmentation with Lateral Wall Technique. Int J Periodontics Restorative Dent. 2020;40:373-380

9. Tükel HC, Tatli U. Risk factors and clinical outcomes of sinus membrane perforation during lateral window sinus lifting: analysis of 120 patients. Int J Oral Maxillofac Surg. 2018;47:1189-1194

10. Cho YS, Chong D, Yang SM, Kang B. Hydraulic transcrestal sinus lift: different patterns of elevation in pig sinuses. Implant Dent. 2017; 26:706.

11. Decco OA, Zuchuat JI, Maldonado Y. Minimally Invasive Technique for Transalveolar Sinus Floor Elevation with a Diamond Burr Used in Skull Base Surgery: A Case Series. IOSR J Dent Med Sci. 2017; 15:11-9.

12. Toffler M. Re. piezoelectric-assisted osteotome-mediated sinus floor elevation: an innovative approach. Implant Dent. 2010;19:458

13. Raghoebar GM, Onclin P, Boven GC, Vissink A, Meijer HJA. Long-term effectiveness of maxillary sinus floor augmentation: A systematic review and meta-analysis. J Clin Periodontol. 2019 Jun;46 Suppl 21:307-318

14. Aghaloo TL, Misch C, Lin GH, Iacono VJ, Wang HL. Bone Augmentation of the Edentulous Maxilla for Implant Placement: A Systematic Review. Int J Oral Maxillofac Implants. 2016; 31:19-30.

15. Starch-Jensen T, Aludden H, Hallman M, Dahlin C, Christensen AE, Mordenfeld A. A systematic review and metaanalysis of long-term studies (five or more years) assessing maxillary sinus floor augmentation. Int J Oral Maxillofac Surg. 2018; 47: 103-116.
16. Ting M, Rice JG, Braid SM, Lee CYS, Suzuki JB. Maxillary Sinus Augmentation for Dental Implant Rehabilitation of the Edentulous Ridge: A Comprehensive Overview of Systematic Reviews. Implant Dent. 2017; 26:438-64.

17. Netto HD, Miranda Chaves MD, Aatrstrup B, Guerra R, Olate S. Bone Formation in Maxillary Sinus Lift Using Autogenous Bone Graft at 2 and 6 Months. Int J Morphol. 2016;34: 1069-1075.

18. Ocak H, Kutuk N, Demetoglu U, Balcıglu E, Ozdamar S, Alkan A. Comparison of Bovine Bone-Autogenic Bone Mixture Versus Platelet-Rich Fibrin for Maxillary Sinus Grafting: Histologic and Histomorphologic Study. J Oral Implantol. 2017; 43:194-201.

19. Whitaker JM, James RA, Lozada J: Histological response and clinical evaluation of heterograft and allograft materials in the elevation of the maxillary sinus for the preparation of endosteal dental implant sites, simultaneous sinus elevation and root form implantation. An eight month autopsy report. J. Oral Implantology 1989; 15:141-144.

20. Garey DJ, Whitaker JM, James RA: The histologic evaluation of the implant interface with heterograft and allograft materials: An eight-month autopsy report. Part II. J. Oral Implantology 1991; 17: 404-408.

21. Maeda T, Kawane T, Horiuchi N. Statins augment vascular endothelial growth factor expression in osteoblastic cells via inhibition of protein prenylation. Endocrinology. 2003;144: 681-92.

22. Nyan M, Sato D, Kihara H, Machida T, Ohya K, Kasugai $\mathrm{S}$. Effects of the combination with alpha-tricalcium phosphate and simvastatin on bone regeneration. Clin Oral Implants Res. 2009; 20: 280-287.

23. Maciel-Oliveira N, Bradaschia-Correa V, Arana-Chavez VE. Early alveolar bone regeneration in rats after topical administration of simvastatin. Oral Surg Oral Med Oral Pathol Oral Radiol Endod. 2011; 112:170-179.

24. Rutledge J, Schieber MD, Chamberlain JM, Byarlay M, Killeen AC, Giannini PJ, et al. Simvastatin application to augment facial jaw bone in a dog model: pilot study. $\mathrm{J}$ Periodontol 2011;82:597

25. Pradeep AR, Rao NS, Bajaj P, Kumari M. Efficacy of subgingivally delivered simvastatin in the treatment of patients with type 2 diabetes and chronic periodontitis: a randomized double-masked controlled clinical trial. J Periodontol. 2013; 84:24-31.

26. Yaghobee S, Panjnoush M, Chokami Rafiei S, Amini Shakib P, Mahmoodi S, Rasouli-Ghahroudi AAR, Pour- 
safar F. Effect of Simvastatin on Bone Regeneration: A Histologic and Histomorphometric Analysis. J Oral Maxillofac Surg. 2020;78:927-934

27. Chen C, Chen C, Wang Z, Wang L, Yang L, Ding M, Ding C, Sun Y, Lin Q, Huang X, Du X, Zhao X, Wang C. Puerarin induces mitochondria-dependent apoptosis in hypoxic human pulmonary arterial smooth muscle cells. PLoS One. 2012;7: e34181.

28. Prasain JK, Jones K, Kirk M et al. Profiling and quantification of isoflavonoids in kudzu dietary supplements by highperformance liquid chromatography and electrospray ionization tandem mass spectrometry. J Agric Food Chem 2003; 51: 4213-4218.

29. Wong KH, Li GQ, Li KM, Razmovski-Naumovski V, Chan K. Kudzu root: traditional uses and potential medicinal benefits in diabetes and cardiovascular diseases. J Ethnopharmacol. 2011; 134:584-607.

30. Wong R, Rabie B. Effect of puerarin on bone formation. Beijing Da Xue Xue Bao 2003;35: 74-77

31. Wu HQ, Guo HN, Wang HQ, Chang MZ, Zhang GL, Zhao YX. Protective effect and mechanism of puerarin on learning-memory disorder after global cerebral ischemiareperfusion injury in rats. Chin J Integr Med 2009; 15:54-59.

32. Wang XX, Wu J, Chiba H, Umegaket K, Yamada K, Ishimi Y. Puerariae radix prevents bone loss in ovariectomized mice. J Bone Miner Metab 2003; 21:268-275.

33. Blarir, HC, Jordan SE, Peterson TG, Stephenal B. Variable effects of ty-rosine kinase inhibitor on avian osteoclastic activity and reduction of bone loss in ovariectiomized rats. J Cell Biochem 1996; 61:629-637.

34. Lundgren S, Cricchio G, Hallman M, Jungner M, Rasmusson L, Sennerby L. Sinus floor elevation procedures to enable implant placement and integration: techniques, biological aspects and clinical outcomes. Periodontol 2000. 2017; 73:103-120.

35. Fermergård R, Astrand P. Osteotome sinus floor elevation and simultaneous placement of implants--a 1-year retrospective study with Astra Tech implants. Clin Implant Dent Relat Res. 2008; 10: 62-69.

36. Nedir R, Nurdin N, Khoury P, et al. Osteotome sinus floor elevation with and without grafting material in the severely atrophic maxilla. A 1-year prospective randomized controlled study. Clin Oral Implants Res. 2013; 24 : 1257-1264.

37. Al-Moraissi EA, Altairi NH, Abotaleb B, Al-Iryani G, Halboub E, Alakhali MS. What Is the Most Effective Re- habilitation Method for Posterior Maxillas With 4 to $8 \mathrm{~mm}$ of Residual Alveolar Bone Height Below the Maxillary Sinus With Implant-Supported Prostheses? A Frequentist Network Meta-Analysis. J Oral Maxillofac Surg. 2019;77: 70.e1-70.e33.

38. Juzikis E, Gaubys A, Rusilas H. Uses of maxillary sinus lateral wall bony window in an open window sinus lift procedure: literature review. Stomatologija. 2018; 20:14-21.

39. Tawil G, Tawil P, Khairallah A. Sinus Floor Elevation Using the Lateral Approach and Bone Window RepositioningI: Clinical and Radiographic Results in 102 Consecutively Treated Patients Followed from 1 to 5 Years. Int J Oral Maxillofac Implants. 2016; 31: 827-834.

40. Jordi C, Mukaddam K, Lambrecht JT, Kühl S. Membrane perforation rate in lateral maxillary sinus floor augmentation using conventional rotating instruments and piezoelectric device-a meta-analysis. Int J Implant Dent. 2018; 4: 3.

41. Toscano NJ, Holtzclaw D, Rosen PS. The effect of piezoelectric use on open sinus lift perforation: a retrospective evaluation of 56 consecutively treated cases from private practices. J Periodontal. 2010; 81: 167-171.

42. Misch CE. Maxillary sinus augmentation for endosteal implants: organized alternative treatment plans. Int J Oral Implantol. 1987; 4:49-58.

43. Raghoebar GM, Batenburg RH, Vissink A, Reintsema H. Augmentation of localized defects of the anterior maxillary ridge with autogenous bone before insertion of implants. J Oral Maxillofac Surg. 1996; 54:1180-6.

44. Babbush CA. Maxillary antroplasty facilitates the insertion of root-form implants. Dent Implantol Update. 1994; 5:1-5.

45. Maron DJ, Fazio S, Linton MF. Current perspectives on statins. Circulation. 2000; 101: 207-213.

46. Balaji SM. Direct v/s Indirect sinus lift in maxillary dental implants. Ann Maxillofac Surg. 2013; 3:148-53.

47. Wang S, Zhang Z, Xia L, et al. Systematic evaluation of a tissue-engineered bone for maxillary sinus augmentation in large animal canine model. Bone. 2010; 46: 91-100.

48. Zhang MY, Qiang H, Yang HQ, Dang XQ, Wang KZ: In vitro and in vivo effects of Puerarin on promotion of osteoblast bone formation. Chin J Integr Med 2012; 18:276-282

49. Wong R, Rabie B. Effect of puerarin on bone formation. Osteoarthritis Cartilage. 2007; 15:894-9.

50. Wang $\mathrm{C}$, Meng MX, Tang XL, et al. The proliferation, differentiation, and mineralization effects of puerarin on osteoblasts in vitro Chin J Nat Med, 2014, 12: 436-442. 
51. Urasopon N, Hamada Y, Cherdshewasart W, Malaivijitnond S. Preventive. Effects of Pueraria mirifica on bone loss in ovariectomized rats. Maturitas. 2008; 59:137-48.

52. Yang F, Zhang R, He F, Wang XX, Zhao S, Yang G. Osteoblast response to Puerarin-loaded porous titanium surfaces: an in vitro study. J Biomed Mater Res A. 2012; 100:1419-1426.

53. Mundy G, Garrett R, Harris S, Chan J, Chen D, Rossini G. Stimulation of bone formation in vitro and in rodents by statins. Science 1999; 286:1946-1949..

54. Rojbani H, Nyan M, Ohya K, Kasugai S. Evaluation of the osteoconductivity of $\alpha$-tricalcium phosphate, $\beta$-tricalcium phosphate, and hydroxyapatite combined with or without simvastatin in rat calvarial defect. J Biomed Mater Res A. 2011; 98: 488-498.

55. Gouda A, Helal E, Ali S, Bakry S, Yassin S. Maxillary sinus lift using osteoinductive simvastatin combined with $\beta$-TCP versus $\beta$-TCP- a comparative pilot study to evaluate simvastatin enhanced and accelerated bone formation. Acta Odontol Scand. 2018; 76: 39-47.

56. Hatano N, Shimizu Y: A clinical long term radiographic evaluation of graft height changes after maxillary sinus floor augmentation with a 2:1 autogenous bone/ xenograft mixture. Clin Oral Implant Res2004; 15: 339- 345.

57. Xu, Shimizu Y: Histomorphometric study of the stability of newly formed bone after elevation of the floor of the maxillary sinus. Br. J of Oral and maxillofacial Surgery. 2005;43, 493-499

58. Panagiotou D, Karaca EÖ, İpçi ŞD, Çakar G, Olgaç V, Yilmaz S. Comparison of two different xenografts in bilateral sinus augmentation: radiographic and histologic findings. Quintessence Int. 2015; 46: 611-619.

59. Nyan M, Sato D, Kihara H, Machida T, Ohya K, Kasugai $S$. Effects of the combination with $\alpha$-tricalcium phosphate and simvastatin on bone regeneration. Clin. Oral Impl. Res. 2009;20; 280-287

60. Allon I, Anavi Y, Allon DM. () Topical simvastatin improves the pro-angiogenic and pro-osteogenic properties of bioglass putty in the rat calvaria critical-size model. J Oral Implantol. 2014; 40: 251-258.

61. Chauhan AS, Maria A, Managutti A. Efficacy of simvastatin in bone regeneration after surgical removal of mandibular third molars: A clinical pilot study. J Maxillofac Oral Surg. 2015; 14: 578-85. 